\title{
Febrile Ulceronecrotic Mucha Habermann Disease: Case Report of a Dark-Skinned Patient
}

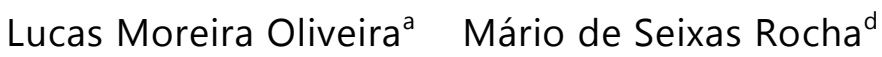 \\ Gyoguevara Sol Patriota $^{\mathrm{e}}$ Gabrielli Tigre Cunha $^{\mathrm{e}}$ Geise Rezende Paiva $^{\mathrm{f}}$ \\ Angelo Sérgio Campos Souza ${ }^{b}$ Airton Campos Fauth ${ }^{a}$ \\ Carlos Geraldo Guerreiro de Moura ${ }^{a}$ Constança Margarida Sampaio Cruz ${ }^{c, d}$ \\ ${ }^{a}$ Internal Medicine, ${ }^{b}$ Dermatologic Service, and ${ }^{c}$ Multidisciplinary Research, Hospital Santo \\ Antonio, Sister Dulce Social Works, ${ }^{\mathrm{d}}$ Medicine and Human Health Postgraduation Course of \\ Bahia School of Medicine and Public Health, ${ }^{\mathrm{e} B a h i a}$ School of Medicine and Public Health, and \\ f Silvany Studard Pathologist Laboratory, Salvador, Brazil
}

\section{Key Words}

Mucha Habermann's disease · Fitzpatrick's skin type VI · Tetracycline $\cdot$ Keloids

\begin{abstract}
A male dark-skinned patient, 33 years old, complaining of a 1-month history of skin lesions in the abdominal region and high fever was admitted to the clinical ward. There were ulcerated and coalescent skin lesions all over the body but sparing the palmar region. The culture of material obtained from the penile lesions was positive for Staphylococcus aureus. He was treated with oxacillin and prednisone. The patient persisted with high fever and skin lesions. After histopathological diagnosis of Mucha Habermann's disease, treatment was started with tetracycline with rapid improvement of the lesions. He was reexamined by the dermatologic service with no recurrences during the 12 months of follow-up. At this time, there was a great number of keloid scars from the skin lesions.
\end{abstract}

\section{Introduction}

Febrile ulceronecrotic Mucha-Habermann disease (FUMHD), described in 1966 by Degos [1], is a variant of pityriasis lichenoides et varioliformis acuta (PLEVA); it differs from the latter by the presence of large ulcerous necrotic lesions associated with high fever and systemic manifestations with a possible fatal outcome [2]. 
There are three theories to explain the pathogenesis of PLEVA: an inflammatory reaction triggered by infectious agents, an inflammatory response secondary to a T-cell dyscrasia and hypersensitivity vasculitis mediated by immune complexes [3].

Forty-two FUMHD cases have been reported in the literature [4]. Nevertheless, only a few cases have been described in Latin America. All these cases were treated in different ways so it is difficult to establish a consensus on the variety of therapeutic measures used. Given the severity of FUMHD and the paucity of data, we report a case with complete remission of skin lesions and fever within 7 days of treatment with tetracycline in a general hospital in Brazil.

\section{Case Report}

A male dark-skinned patient (Fitzpatrick's skin type VI), 33 years old, was admitted to the medical clinic ward complaining of a 1-month history of skin lesions in the abdominal region. After 2 weeks he developed high fever $\left(39.5^{\circ} \mathrm{C}\right)$ associated with an abrupt spread of lesions to the chest region, genitals and limbs, with changes in the pattern. There was no complaint of pain or itching associated with the skin lesions.

On physical examination, there were skin lesions in different evolutionary stages with reticular distribution, many of them ulcerated and coalescent (fig. 1), all over the body but sparing the palmar region, soles, scalp and ears. On the trunk, the skin lesions had varioliform aspect. There were ulcerated lesions in the penile region, with yellowish discharge (fig. 2). Other mucous membranes were not involved. There were no signs of gastrointestinal, neurological, cardiac or pulmonary involvement on physical examination. Chest X-ray showed no pathological findings.

Laboratory findings included total and differential counting of blood cells, examination of renal and hepatic function, protein electrophoresis, immunoglobulins, C3, C4, antinuclear antibodies, serology for hepatitis B and C, HIV I and II, Epstein-Barr virus, cytomegalovirus, herpes simplex, toxoplasmosis and search for Treponema pallidum. All tests were normal or negative except for the culture of material obtained from penile ulcerated lesions, which were positive for methicillin-sensitive Staphylococcus aureus (MSSA).

Treatment was started with oxacillin $6 \mathrm{~g} /$ day, intravenously, to treat secondary infection. Prednisone, $60 \mathrm{mg}$ daily, orally, was used to induce immunosuppression. The patient was treated for his infected penile region (fig. 2), but maintained daily high fever and skin lesions on the trunk and limbs.

Histopathological findings confirmed the presence of lesions in different stages of evolution. First, there was a recent skin lesion with hyperkeratosis and acanthosis (fig. 3a). Later, there was hyperkeratosis with hydropic degeneration of the basal layer and hemorrhagic focus (fig. 3b). There were well-established lesions with necrosis and ulceration of the epidermis (fig. 3c). A prominent inflammation with perivascular lymphocytic infiltrate extending throughout the dermis without atypia was also noted (fig. 3d).

After the skin biopsy, treatment was started with tetracycline $500 \mathrm{mg}$ every 6 hours, orally, progressing with rapid improvement of the lesions and with no fever within 7 days of tetracycline administration. The treatment was maintained with tetracycline $2 \mathrm{~g} /$ day for 4 weeks followed by 2 months with $1 \mathrm{~g} /$ day. There was no recurrence or progression to malignancy in a follow-up of 1 year in outpatient dermatology. After 12 months of monitoring, the patient is in excellent general condition. On examination of the skin, a great number of keloid scars from the skin lesions were found (fig. 4). 


\section{Discussion}

FUMHD is a rare and potentially fatal variant of PLEVA. Small eruptions may precede the course of the disease to fulminant ulcer-necrotic lesions spreading over the body surface and associated with high fever and sepsis, among other systemic manifestations. The disease typically affects children and adults in the third decade of life $[2,4,5]$.

In fact, our patient had a similar course to that described in the literature, including secondary infection by MSSA, requiring antibiotics and oral corticosteroids, but without control of fever and without disappearance of lesions. Only after treatment with tetracycline for 7 days $2 \mathrm{~g} /$ day was there full remission of the frame, which is consistent with previous studies that reported better response to tetracycline in adults compared to children; however, the complete response in our patient occurred in less time (7 days) than that of tetracycline-treated patients reported in the literature (10 days) $[5,6]$. This sequence of events suggests that oxacillin and steroids were active in secondary infection, while the tetracycline was active in the Mucha-Habermann disease [2].

Tetracycline and analogues, regardless of their antibiotic properties, have antiinflammatory, [7-15] proteolytic [16-19] effects, and are also inhibitors of angiogenesis and apoptosis [20, 21].The anti-inflammatory activity described in the literature includes: inhibition of human lymphocyte proliferation [7], suppression of chemotaxis and neutrophil migration, and inhibition of transmigration of T lymphocytes [7-10]. Although there already is evidence of their immunomodulatory effects, additional clinical and laboratory studies are needed to confirm these properties in this class of antibiotics. However, to date, tetracyclines represent first-line drugs for the treatment of PLEVA, especially in adults [22].

Histopathology revealed typical findings of FUMHD with polymorphic lesions that evolve from hyperkeratosis and acanthosis to ulceration and necrosis of the epidermis, and the presence of a lymphocytic infiltrate obscuring the epidermis/dermis junction as Szymanski emphasizes in his study [23].

The patient was followed by the dermatologic service with no recurrences and no progress to malignancy during 12 months of follow-up. Tetracycline was maintained at a dose of $2 \mathrm{~g} /$ day until the end of the first month and $1 \mathrm{~g}$ /day for 2 more months. Relapses have been described as less common in adults compared to children [5].

Case reports of FUMHD have recommended high-dose immunosuppressive therapy in combination with antibiotics or virostatic drugs, while some authors also described partial success in immunosuppressive monotherapy with methotrexate or cyclosporine or a combination of one of these with high-dose glucocorticoids. Among antibiotics, the best results have been related to erythromycin for children and to tetracycline for adults [24, 25].

No recurrence has been shown with high doses of corticosteroids and antibiotics in the first weeks (complete resolution of the lesions) and maintenance treatment for over 2-6 months with half doses of antibiotics [26]. Because of the severity of disease in the present study and in an effort to avoid recurrences, the patient was treated with tetracycline at a dose of $2 \mathrm{~g}$ /day until the end of the first month and $1 \mathrm{~g} /$ day for 2 more months.

The finding of keloids as scars from the skin lesions was an atypical manifestation of the disease when compared to the other case reports (fig. 4). Keloids are more common in individuals of African descent and are caused by proliferation of dermal fibroblasts in the healing process, with excessive deposition of extracellular matrix components, especially collagen, fibronectin, elastin, proteoglycans, and growth factors such as transforming growth factor [27]. The vast majority of case reports of FUMHD have described hypopigmented atrophic scars instead of those found in our study $[2,4,6]$. 
Tetracycline has been reported by most authors as first-line treatment in adults with FUMHD $[4,5]$. The immunomodulatory action of this drug may keep the clinical manifestations of Mucha-Habermann disease suppressed [7-14]. Early diagnosis and treatment of this disease can decrease the chance of a fatal outcome in these patients. Considering the paucity of reported cases, new clinical and laboratory studies are needed to confirm and better understand the action of tetracycline in this disease, and also to address if ethnicity represents some sort of predisposition to different types of scars.

\section{References}

1 Degos R, et al: Le Parapsoriasis ulcero-necrotique hyperthermique. Ann Derm Syph 1966;93:481-496.

-2 Burke DP, Adams RM, Arundell FD: Febrile ulceronecrotic Mucha Habermann's disease. Arch Dermatol 1969;100:200-206.

-3 Rivera R, Ortiz P, Rodriguez-Peralto JL, et al: Febrile ulceronecrotic lichenoides et varioliformis acuta with atypical cells. Int J Dermatol 2003;42:26-28.

4 Perrin BS, Yan AC, Treat JR: Febrile ulceronecrotic Mucha-Habermann disease in a 34-month-old boy: a case report and review of the literature. Pediatr Dermatol 2012;29:53-58.

$\checkmark 5$ Wahie S, Hiscutt E, Natarajan S, Taylor A: Pityriasis lichenoides: the differences between children and adults. Br J Dermatol 2007;157:941-945.

6 Bowers S, Warshaw M: Pityriasis lichenoides and its subtypes. J Am Acad Dermatol 2006;55:557-572.

7 Thong YH, Ferrante A: Inhibition of mitogen-induced human lymphocyte proliferative responses to tetracycline analogues. Clin Exp Immunol 1979;35:443-446.

-8 Martin RR, Warr GA, Couch RB, Yeager H, Knight V: Effects of tetracyclines on leukotaxis. J Infect Dis 1974;129:110-116.

-9 Esterly NB, Furey NL, Flanagan LE: The effect of antimicrobial agents on leukocyte chemotaxis. J Invest Dermatol 1978;70:51-55.

10 Brundula V, Rewcastle NB, Metz LM, Bernard CC, Yong VW: Targeting leukocyte MMPs and transmigration: minocycline as a potential therapy for multiple sclerosis. Brain 2002;125:1297-1308.

11 Plewig G, Schopf E: Anti-inflammatory effects of antimicrobial agents. An in vivo study. J Invest Dermatol 1975;65:532-536.

-12 Kloppenburg M, Breedveld FC, Terwiel J, Mallee C, Dijkmans BAC: Minocycline in active rheumatoid arthritis: a double blind, placebo-controlled trial. Arthritis Rheum 1994;37:629-636.

13 Pruzanski W, Greenwald RA, Street IP, Laliberte F, Stefanski E, Vadas P: Inhibition of enzymatic activity of phospholipase A2 by minocycline and doxycycline. Biochem Pharmacol 1992;44:1165-1170.

14 Ritchlin CT, Haas-Smith SA, Schwarz EM: Minocycline but not doxycycline upregulates IL-10 production in human synovio-cytes, mononuclear cells and synovial explants. Arthritis Rheum 2000;43(suppl 9):S345.

15 Amin AR, Attur MG, Thakker GD, Patel PD, Vyas PR, Patel RN, et al: A novel mechanism of action of tetracyclines: effects of nitric oxide synthases. Proc Nat Acad Sci 1996;93:14014-14019.

16 Golub LM, Lee HM, Ryan ME, Giannobile WV, Payne J, Sorsa T: Tetracyclines inhibit connective tissue breakdown by multiple non-antimicrobial mechanisms. Adv Dent Res 1998;12:12-26.

17 Golub LM, Lee HM, Lehrer G, Nemiroff A, McNamara TF, Kaplan R, et al: Minocycline reduces gingival collagenolytic activity during diabetes: preliminary observations and a proposed new mechanism of action. J Periodont Res 1983;18:516-520.

18 Golub LM, Ramamurthy NS, McNamara TF, Greenwald RA, Rifkin BR: Tetracyclines inhibit connective tissue breakdown: new therapeutic implications for an old family of drugs. Crit Rev Oral Biol Med 1991;2:297321.

19 Hanemaaijer R, Visser H, Koolwijk P, Sorsa T, Salo T, Golub LM, et al: Inhibition of MMP synthesis by doxycycline and chemically modified tetracyclines (CMTs) in human endothelial cells. Adv Dent Res 1998;12:114-118.

-20 Yrjanheikki J, Keinanen R, Pellikka M, Hokfelt T, Koistinaho J: Tetracyclines inhibit microglial activation and are neuroprotective in global brain ischemia. Proc Natl Acad Sci 1998;95:15769-15774.

-21 Yrjanheikki J, Tikka T, Keinanen R, Goldstein G, Chan PH, Koistinaho J: A tetracycline derivative, minocycline, reduces inflammation and protects against focal cerebral ischemia with a wide therapeutic window. Proc Natl Acad Sci 1999;96:13496-13500.

22 Ersoy-Evans S, Greco MF, Mancini AJ, et al: Pityriasis lichenoides in childhood: a retrospective review of 124 patients. J Am Acad Dermatol 2007;56:205-210.

23 Szymanski FJ: Pityriasis lichenoides et varioliformis acuta: histopathological evidence that it is an entity distinct from parapsoriasis. Arch Derm 1959;79:7-16. 
Moreira Oliveira et al.: Febrile Ulceronecrotic Mucha Habermann Disease: Case Report of a Dark-Skinned Patient

24 Ito N, Ohshima A, Hashizume H, Takigawa M, Tokura Y: Febrile ulceronecrotic Mucha-Habermann's disease managed with methylprednisolone semipulse and subsequent methotrexate therapies. J Am Acad Dermatol 2003;49:1142-1148.

25 Kim HS, Yu DS, Kim JW: A case of febrile ulceronecrotic Mucha-Habermann's disease successfully treated with oral cyclosporin. J Eur Acad Dermatol Venereol 2007;21:272-273.

-26 Sotiriou E, Patsatsi A, Tsorova C, Lazaridou E, Sotiriadis D: Febrile ulceronecrotic Mucha-Habermann disease: a case report and review of the literature. Acta Derm Venereol 2008;88:350-355.

27 Kelly AP: Medical and surgical therapies for keloids. Dermatol Ther 2004;17:2128.

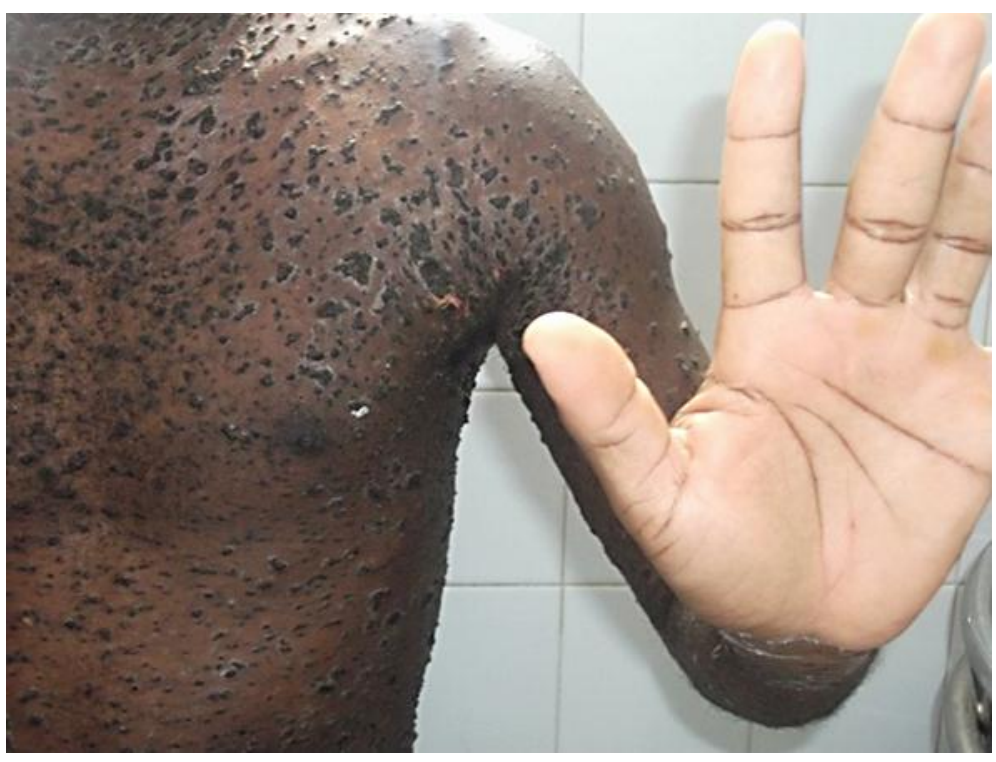

Fig. 1. Crusted ulcerated polymorphic lesions following a reticular pattern on the trunk, upper limb flexor zone and upper limbs, sparing the palms. 


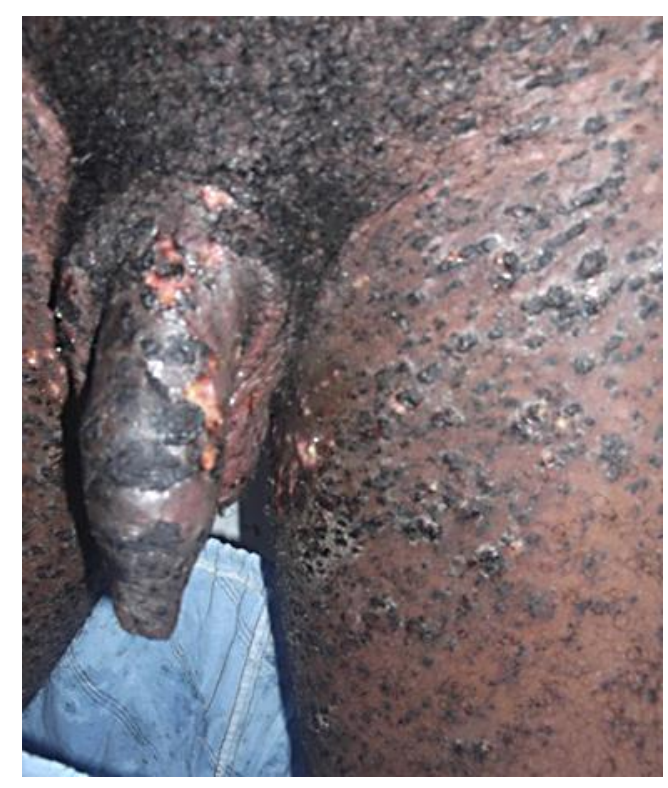

Fig. 2. Involvement of the genital region with secondary infection by S. aureus.

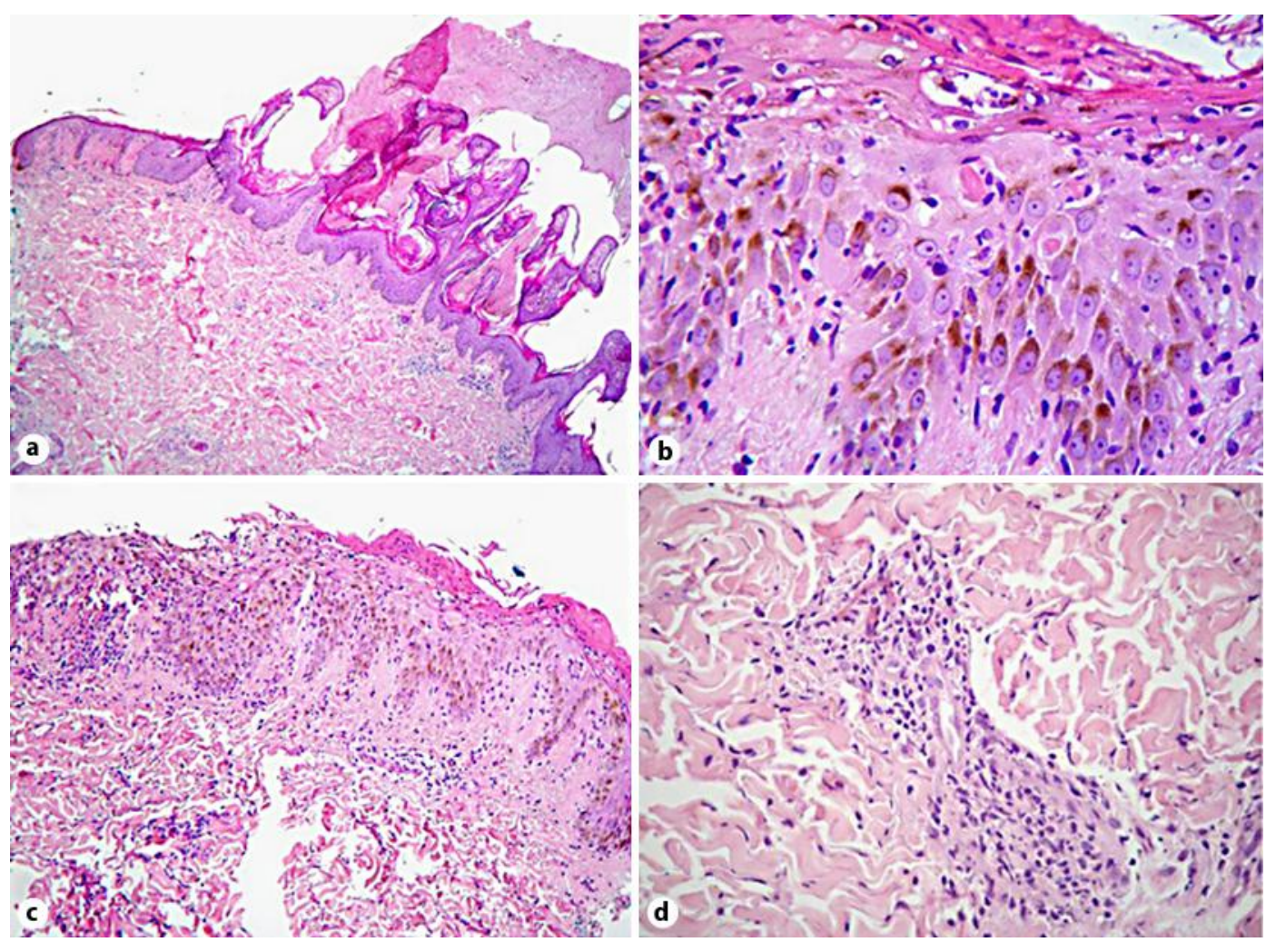

Fig. 3. a Recent skin lesion shows hyperkeratosis and acanthosis. b Presence of hyperkeratosis with foci of hemorrhage and degeneration of the basal layer. c Well-established lesion with necrosis and ulceration of the epidermis. $\mathbf{d}$ Perivascular lymphocytic inflammatory infiltrate in the dermis without atypia. 


\section{Case Reports in Dermatology}

Moreira Oliveira et al.: Febrile Ulceronecrotic Mucha Habermann Disease: Case Report of a Dark-Skinned Patient

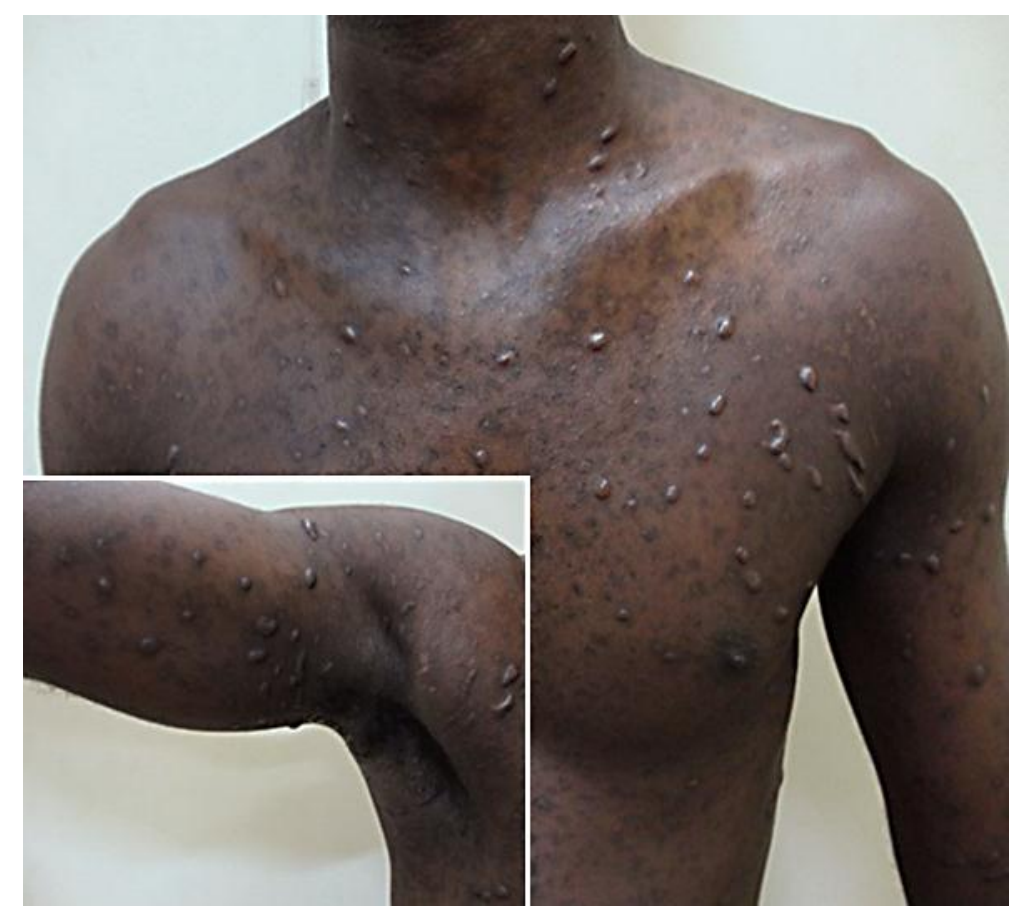

Fig. 4. Hyperchromic spots distributed throughout the body and keloid scarring lesions predominantly on the thorax and upper limbs. 